\title{
Concise asymmetric syntheses of streptazone $A$ and abikoviromycin
}

\author{
Gustav J. Wørmer, Nikolaj L. Villadsen, Peter Nørby, Thomas B. Poulsen* \\ Department of Chemistry, Aarhus University, Langelandsgade 140, DK-8ooo, Aarhus C, Denmark.
}

\begin{abstract}
Streptazone A and abikoviromycin are related alkaloids that both feature an unusual arrangement of reactive functionalities within an underlying compact tricyclic ring system. Here, we report a highly concise asymmetric synthesis of both natural products. The developed route first constructs another member of the streptazones, streptazone B1, using a rhodium-catalyzed distal selective allene-ynamide Pauson-Khand reaction as the key transformation. A regio- and enantioselective epoxidation under chiral phase-transfer catalytic conditions was then achieved to directly make streptazone A in 8 steps overall. A chemoselective, iridium-catalyzed reduction of the enaminone-system was employed to make abikoviromycin in one additional step. Studies of the intrinsic reactivity of streptazone A towards the cysteine mimic, $N$-acetylcysteamine, revealed unanticipated transformations, resulting in thiol conjugation to both the hindered tertiary carbon of the double allylic epoxide and in bis-thiol conjugation which may proceed via formation of a cyclopentadienone intermediate. With flexible access to these compounds, studies aimed to identify their direct biological targets are now possible.
\end{abstract}

Natural products that feature unusual constellations of reactive chemical groups are fascinating outcomes of microbial biosynthesis and may constitute unique opportunities for discovery of interesting biological activity. ${ }^{1}$ The streptazones $^{2,3}$ (Fig. 1A) are members of a larger family of piperi-

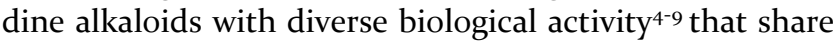
an interesting [4.3.0] bicyclic core (Fig. 1A,B). Streptazoline $3^{4,10}$ has been the subject of sustained interest from a series of laboratories due to the challenging tricyclic urethane core structure and the ( $Z$ )-exocyclic ethylidene side chain. ${ }^{11}$ Overall, the different family members are defined by variations in oxidation state and modifications to the underlying hexahydrocyclopenta[b]pyridine scaffold. We have taken special interest in streptazone A (1) which is reported to be a potent inhibitor of liver cancer cell growth (HepG2, $\left.\mathrm{GI}_{50}=<0.1 \mu \mathrm{M}\right){ }^{2} \mathbf{1}$ features the unique constellation of an enaminone, a Michael acceptor, and a bis-allylic epoxide. We were intrigued by the compact nature of the multiple electrophilic sites embedded in this small molecule (MW = $177 \mathrm{~g} / \mathrm{mol}$ ) as well as the absence of information about direct biological targets, and the lack of known methods to assemble the structure. Notably, other members of the family that feature a related fused epoxide-core, kobutimycin $\mathrm{A}-\mathrm{B}^{7}$, hatomamicin ${ }^{8}$, and abikoviromycin $(4)^{6,12}$ have also been associated with potent biological activity, with 4 differing from 1 by a different oxidation state at $C_{7}$. In this communication, we report the first asymmetric synthesis of (+)-streptazone A (1) in 8 steps, the assignment of its absolute configuration, and the discovery of conditions for selectively transforming $\mathbf{1}$ into abikoviromycin (4) in a single operation. Finally, we uncover an unanticipated spectrum of thiol-reactivity inherent within the streptazone A ring system.

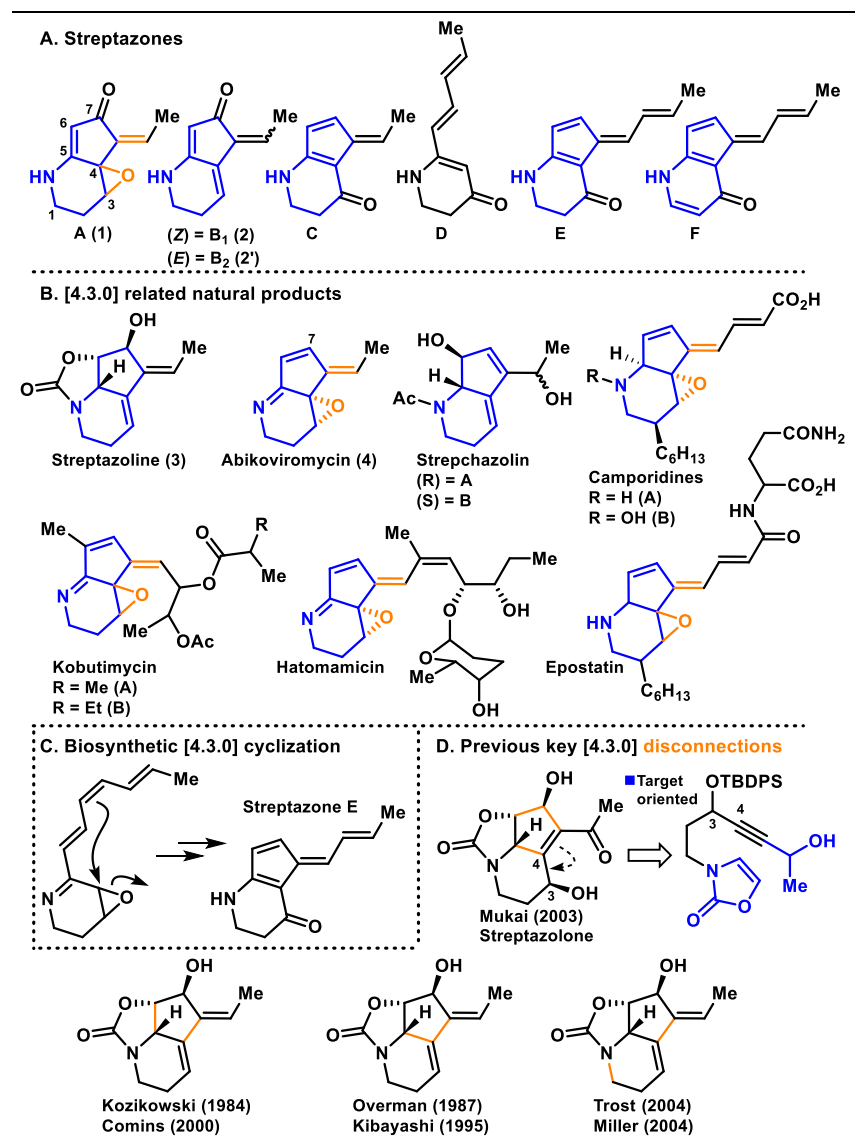

Figure 1. Chemical structures of (A) the streptazones and (B) additional family members. (C) [4.3.0]-assembly during the biosynthesis of streptazone E. (D) Different synthesis strategies towards streptazolin and streptazolone. 
In contrast to the plethora of syntheses of $\mathbf{3}$, no synthesis has been reported for any epoxide-containing member of the family. ${ }^{11}$ It has been proposed that an epoxide facilitates the formation of the [4.3.o] core by a ring-opening event during the biosynthesis of streptazone $\mathrm{E}^{13}$ and the camporidines ${ }^{9}$ (Fig. $1 \mathrm{C}$ ), however, the subsequent events that result in re-closure/re-installation of the epoxide and further oxidations are not known in detail. Arguably, any synthetic strategies targeting this functionality are likely to be challenging due to the expected tendency for carbocation formation as a result of the double allylic tertiary position at $\mathrm{C}_{4}$ (Scheme 1). Indeed, 4 has been reported to be highly unstable and to undergo polymerization even at $-50{ }^{\circ} \mathrm{C}$ when handled too concentrated ${ }^{12 c}$, thus pointing to an intrinsic structural lability of such systems.

\section{Scheme 1. Retrosynthetic analysis}

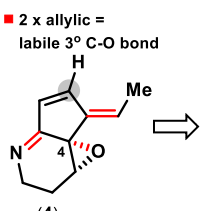

(4)

R Ynamide $\mathrm{N}-\mathrm{C}(\mathrm{sp})$

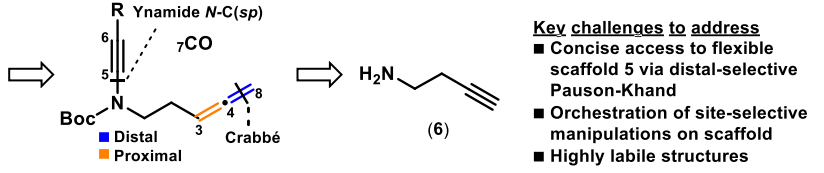

Mindful of the expected challenges associated with the epoxide, we opted to pursue a strategy that would install this group at the final stages. Indeed, we realized the potential for developing a direct approach in which 2 could be converted first to 1 and then further to 4 through sequential selective epoxidation and reduction. However, based on the reported ${ }^{13} \mathrm{C}$ NMR chemical shifts of $\mathbf{2}^{2}$, the potential for conducting a selective $\mathrm{C}_{3}-\mathrm{C}_{4}$ epoxidation was hard to predict and methodologies describing the subsequent reduction was absent in the literature. This disconnection is therefore directly addressing two challenging and fundamental transformations for this class of compounds. Access to 2 would be possible via the highly simplified [4.3.0] bicyclic core 5 that was revealed by disconnecting the ethylidene sidechain (Scheme 1).

To develop an efficient route to 5, we judiciously evaluated the prior syntheses of 3 and streptazolone (Fig. 1D) and found the intramolecular oxazolidinone Pauson-Khand cycloaddition utilized by Mukai and co-workers ${ }^{11 \mathrm{e}}$ appealing, however, not directly applicable to our purpose: First, the cyclic urethane is central for the construction of the tricyclic ring system and variations to this particular core were unlikely to be trivial. Second, the Pauson-Khand cycloaddition product obtained would require a challenging isomerization of the olefin to the desired $\mathrm{C}_{3}-\mathrm{C}_{4}$ position. Instead, we envisioned that the olefin could be positioned advantageously by a distal selective intramolecular alleneynamide Pauson-Khand cyclization, which, interestingly, is unprecedented in the literature for [4.3.o] scaffolds. The ynamide functionality has been studied extensively by several groups to construct the rather difficult $N-\mathrm{C}(s p)$ bond directly and different protecting groups may be applied in the transformation. ${ }^{14}$ This analysis then converged to commercial but-3-yn-1-amine hydrochloride 6 as an optimal starting material.

The synthesis was initiated using the Crabbé homologation $^{15}$ of Boc-protected 6 to deliver allene 7 in $76 \%$ yield in multigram quantities (16 g isolated) over two steps. Next, we turned our attention to establish the acyclic bulky carbamate $\mathrm{N}-\mathrm{C}(\mathrm{sp})$ bond. Several methodologies were evaluated $^{14}$ which generally failed to provide reproducible results for a scalable synthesis. Initial attempts based on TMS-bromoacetylene employing the $2^{\text {nd }}$ generation copper catalyzed ynamide synthesis delivered the allene tethered ynamide 8a in $<1 \%$ yield whereas the TIPS-bromoacetylene and the TES-bromoacetylene, resulting in $\mathbf{8 b}$ and $\mathbf{8 c}$ respectively, performed significantly better after optimization (see Table 1 in SI). ${ }^{16}$ Our initial intramolecular alleneynamide Pauson-Khand cyclization was tested on all three ynamides (8a-8c) using the commonly employed $\left[\mathrm{Rh}(\mathrm{CO})_{2} \mathrm{Cl}\right]_{2}$ for regioselectively favoring the distal $\pi$-bond of the allene in the cyclization. ${ }^{17-19}$ Furthermore, for safe handling of $\mathrm{CO}$ gas, we studied the reaction utilizing a twochamber system developed by Skrydstrup et al. where stoichiometric $\mathrm{CO}$ is delivered ex situ from a palladium catalyzed decarbonylation of a solid precursor (see SI). ${ }^{20}$ Indeed, we found that the cyclization worked on all three substrates which establishes ynamides as functional precursors for rhodium-catalyzed Pauson-Khand cyclization to deliver [4.3.o] scaffolds. To our knowledge, only catalytic molybdenum has been employed in an intramolecular allene-ynamide cyclization, however, to access [3.3.0] scaffolds. ${ }^{21}$ In our hands, 8c was balanced appropriately for both ynamide accessibility and performance in the early cyclization attempts. After evaluation of several distal selective catalysts (scheme 2, step d), we found $[\mathrm{Rh}(\mathrm{CO}) \mathrm{Cl}(\mathrm{dppp})]_{2}$ the most suitable for a scalable synthesis (66\% yield on a $19 \mathrm{mmol}$ scale). With rapid access to the [4.3.0] core secured, installation of the C8-ethylidene group was next. Following our retrosynthetic analysis, the aldol disconnection was initiated by $\mathrm{C} 8$ alkylation using the lithium enolate generated with LiHMDS that could subsequently be treated with acetaldehyde to afford a $60: 40 \mathrm{dr}$ mixture of $\beta$-hydroxy ketones in $74 \%$ yield. The mixture of diastereoisomers could readily undergo dehydration using Burgess reagent to predominantly afford the syn eliminated $\alpha, \beta$-unsaturated ketones 11 in $82 \%$ yield as a 55:45 cis/trans mixture. ${ }^{22}$ To our delight, protodesilylation and $\mathrm{N}$-Boc deprotection could be achieved in a single operation using diluted TFA which upon basic work-up delivered $\mathbf{2}$ and $\mathbf{2}$ ' in $89 \%$ yield.

Progressing forward, $\mathbf{2}$ and $\mathbf{2}$ ' were separated using standard chromatography which enabled us to study the direct epoxidation of 2. An extensive work was put into this particular transformation - testing both racemic and a range of established asymmetric procedures to probe the overall reactivity of the tris-olefins in $\mathbf{2} / \mathbf{2}$ '. Generally, we found that electrophilic epoxidations using $m$-CPBA, DMDO etc. under different conditions delivered complex mixtures, 
presumably as a direct consequence of the more nucleophilic free enaminone system. Next we speculated whether the $\mathrm{C}_{3}-\mathrm{C}_{4}$ olefin (scheme 1 ) principally could be viewed as a $\gamma-\delta$ unsaturated ketone and become activated under Lewis acid- or Brøndsted acid catalysis. In our hands, however, such conditions either resulted in decomposition or reisolation of starting material. Jacobsen's manganese based system ${ }^{23}$ (Scheme 2, step h, entry 1) did allow us to identify trace formation of $\mathbf{1}$ but unfortunately, the methodology failed to deliver improvement after substantial experimentation and was furthermore limited by irreproducible results on scales greater than $0.05 \mathrm{mmol}$. To our delight, we found that Shibasaki's lanthanum-BINOL system $^{24}$ (entry 2 ) indeed delivered $\mathbf{1}$, though as a racemic mixture. Upon rational exclusion of each component in the system, it was clear that lanthanum was irrelevant for the epoxidation while cumene hydroperoxide (CHP) at elevated temperature sluggishly could deliver 1 regioselectively. With catalytic DBU, we started to obtain promising results (entry 3 ) and conversion of $\mathbf{2}$ was further improved using TBAI as phase-transfer catalyst (PTC), although $\mathbf{1}$ was still only formed in small amounts (entry 4). This prompted us to investigate cinchona-based PTCs. ${ }^{25}$ Gratifyingly, the yield of $\mathbf{2}$ increased significantly and stereoinduction was also obtained (entry 5-6). After further optimization (see Table 2 in SI) we found that the commercial catalyst 12 could deliver 1 in $62 \%$ yield with $72 \%$ ee $(>99 \%$ ee after recrystallization). Subsequent derivatization of $(+)-1$ with ferrocene- $\mathrm{CO}_{2} \mathrm{Cl}$ enabled us to determine the absolute configuration of $(+)-1$ by X-ray crystallography.

Scheme 2. Synthesis of streptazone A and abikoviromycin
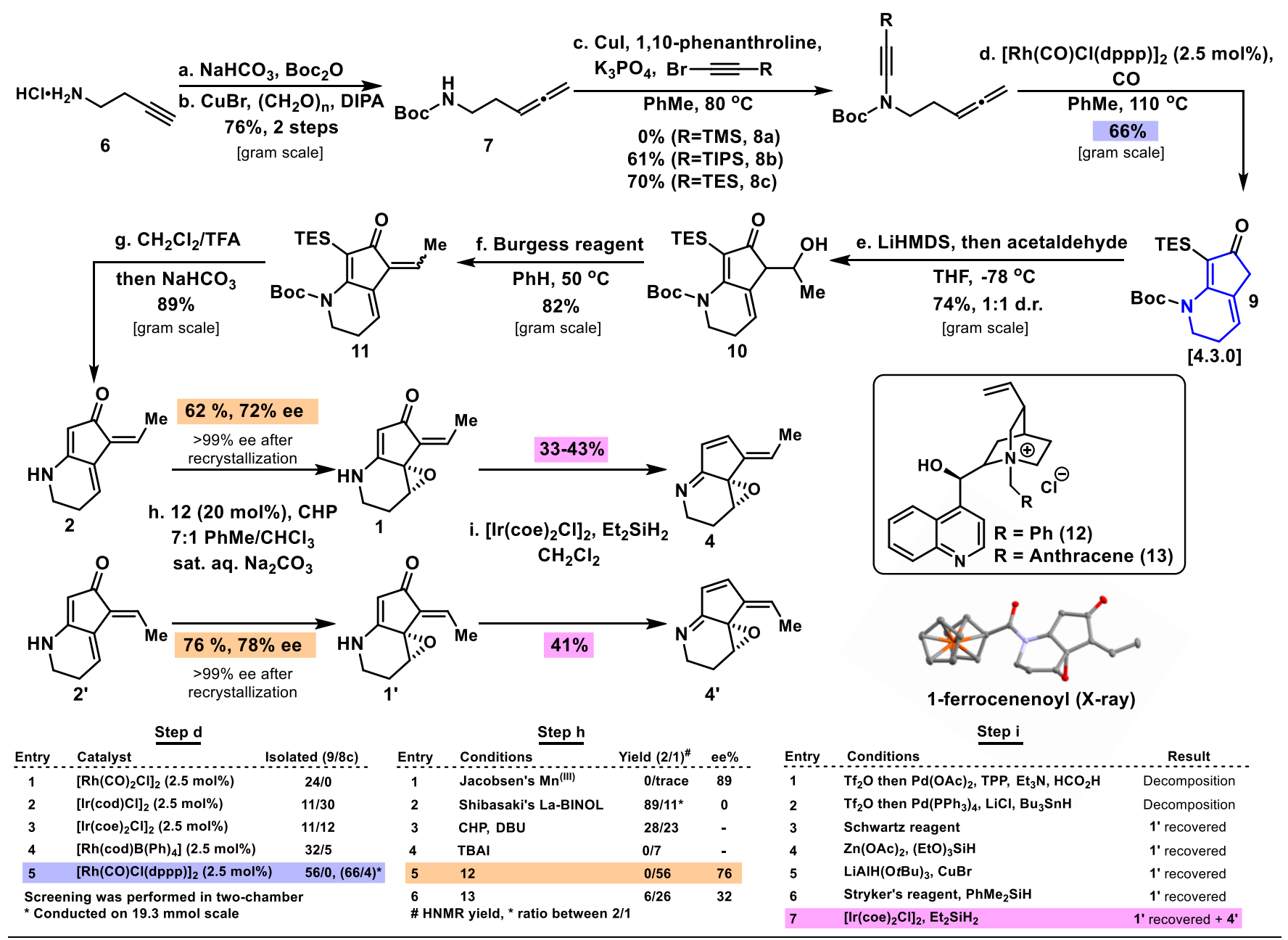

$\mathbf{1}$ and $\mathbf{4}$ differ only by oxidation level. Although the potential biosynthetic connection between these two compounds currently remains elusive, access to 1 prompted the question if a single, selective reduction to form $\mathbf{4}$ could be realized to directly access the imine [4.3.o] subclass. Albeit a highly appealing synthetic option, the direct conversion from a free cyclic enaminone to the corresponding conjugated imine is, however, to our knowledge not precedented in the literature. This particular transformation is complicated by several factors: 1 ) multiple sites in $\mathbf{1}$ are prone to alternate reductions, hereof the labile epoxide and the Michael acceptor, 2) feasible over-reduction upon generation of the conjugated imine, 3) the product $\mathbf{4}$, is reportedly highly unstable. 
A: Conjugation of $\mathrm{N}$-acetylcysteamine to 1
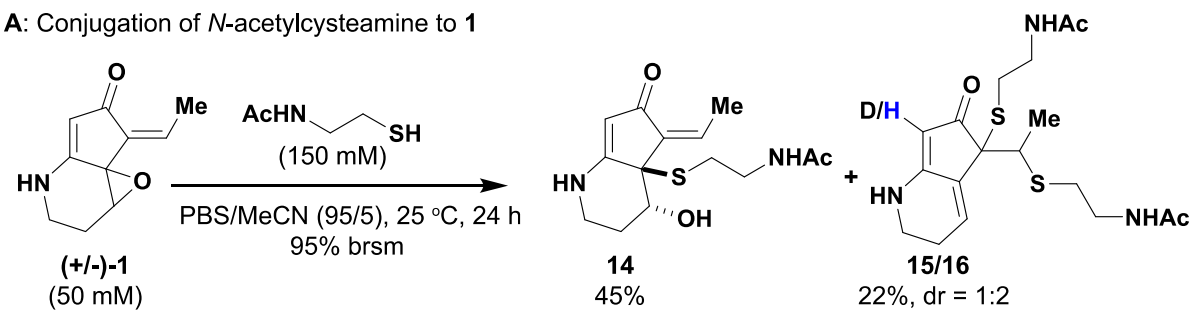

B: HPLC-traces

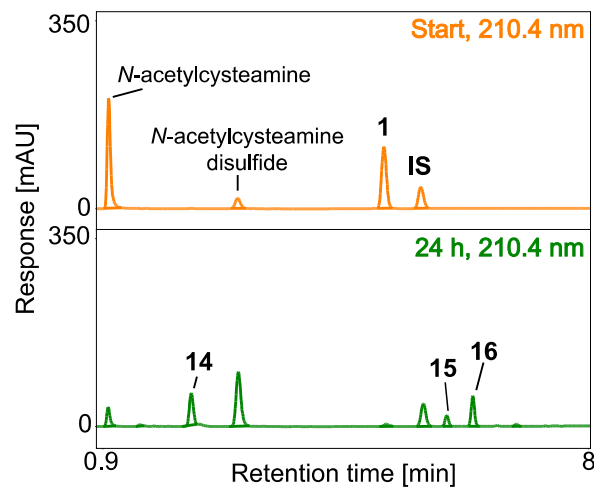

D: Proposed mechanism for formation of $15 / 16$

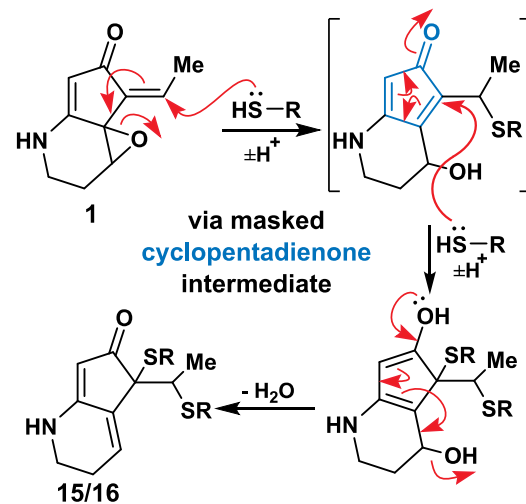

C: X-ray structure of 1
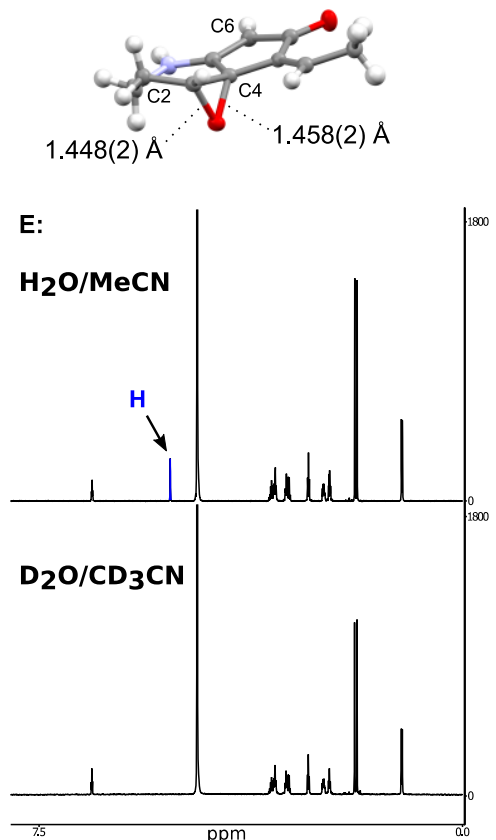

Figure 2. Studies of thiol-conjugation to streptazone A reveals dichotomous reactivity.

We decided to engage in a screen for reduction conditions utilizing the geometric isomer l' under the assumption that the overall outcome would be representative also for 1. Our initial effort was based on the hypothesis that enaminones have increased electron density at the carbonyl which should render the system more susceptible for $O$ activation. When $\mathbf{r}^{\prime}$ was subjected to $\mathrm{Tf}_{2} \mathrm{O}$, we indeed observed formation of the $O$-triflated triflate salt which was immediately subjected to reductive conditions under palladium catalysis (Scheme 1, step i, entry 1-2) ${ }^{26,27}$, however, only decomposition of the starting material was observed. Next we tested methodologies reported for secondary amide reduction by metal catalyzed reductions (entry 3-4) 28,29 with neither indication of imine nor amine formation. Moreover, we evaluated the possibility of a 3 -step sequence by initial 1,4-hydride copper-catalyzed reduction of the enaminone, triflation and reduction and lastly relying on the reported enzymatic reoxidation to 4 by SF-973B oxidoreductase. ${ }^{30-32}$ This idea, however, fell short of the goal already in the initial 1,4 hydride reduction (entry 5-6). Finally, inspired by the recently reported total synthesis of Herquline $\mathrm{B}$ and $\mathrm{C}$ by Baran and co-workers employing the iridium-diethylsilane system developed by Cheng and Brookhart, we ultimately found the reduction-system applicable to directly deliver the imine product 4' (entry 7)

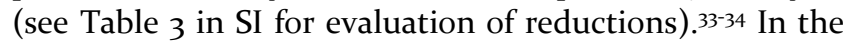
case of $\mathbf{1}$, the reduction proceeded slower but it nonethe- less afforded 4 in $43 \%$ overall best yield, (see SI for a discussion of general stability of 4 ). In the case of ' 1 ', simply increasing the reaction time pushed the reaction toward the dihydro adduct whereas $\mathbf{1}$ required additional reductant to deliver dihydroabikoviromycin (see SI). ${ }^{6,35}$ Hence, the system may be employed to afford both the imine- and the amine [4.3.0] bicyclic classes by careful reaction control.

Finally, we investigated the electrophilic properties of $\mathbf{1}$ towards a biological thiol mimetic, $N$-acetylcysteamine, at physiological $\mathrm{pH}$ (Fig. 2A). 95\% conversion was obtained after $24 \mathrm{~h}$ thereby confirming the intrinsic reactivity of the natural product towards thiols. Surprisingly, we were able to identify three major thiol conjugates by analytical RPHPLC, which we successfully isolated with the major thiol conjugate corresponding to epoxide opening (Fig. 2A,B). As evident by careful 2D NMR analysis, the epoxide was curiously opened at the tertiary position, not the secondary. We speculate that the observed regioselectivity is a direct consequence of the double allylic contribution to the $\sigma^{*} \mathrm{C}-\mathrm{O}$ bond that in turn favors the tertiary carbon for incoming nucleophiles. To further elaborate on this effect, we were able to crystallize the natural product which indeed revealed that this particular $\mathrm{C}-\mathrm{O}$ bond was slightly elongated in comparison to the other (Fig. $2 \mathrm{C}$ ). The remaining two conjugates corresponded to a set of diastereoisomers $(\mathbf{1 5 / 1 6 )}$ and were unmistakably the product of double addition of $\mathrm{N}$-acetylcysteamine (Fig. 2A,B). Again, 
we were surprised by the behavior performed by $\mathbf{1}$, as it became evident from HMBC couplings, that the additions corresponded to a completely different reaction path, in this case initiated via the Michael acceptor. We speculate that initial 1,4-addition induces epoxide opening via the corresponding enolate and, in turn, unmasks a highly reactive cyclopentadienone electrophile (possibly stabilized by the fused amine) that undergoes a subsequent nucleophilic addition at the $\alpha$-position and ultimately results in dehydration (Fig. 2D). To gain mechanistic insight of the $\alpha$-addition, we conducted the conjugation in $\mathrm{D}_{2} \mathrm{O} / \mathrm{CD}_{3} \mathrm{CN}$ and found that $\mathrm{C} 6$ had undergone full deuterium exchange, thereby suggesting that $\alpha$-addition principally may be viewed as a 1,6-addition (Fig. 2E). To our knowledge, this is the first evidence supporting a masked cyclopentadienone natural product electrophile.

From a biological perspective, this data supports that 1 likely acts as a cysteine-reactive natural product that furthermore demonstrate the reactivity characteristic for some "molecular glues" by having multiple electrophilic sites. ${ }^{36}$ We anticipate that this highly peculiar reactivity will manifest itself in biological studies of this natural product family. Attempts to reproduce the reported toxicity against HepGz liver cancer cells were, in our hands, not successful with $\mathbf{1}$ (of any of its isomers) showing negligible toxicity. This, along with the intrinsic reactivity of $\mathbf{1}$ that we have observed, underscores the importance of mapping the covalent targets of $\mathbf{1}$.

In summary, we have developed the first synthesis of streptazone $B_{1} / B_{2}$, streptazone $A$, abikoviromycin and dihydroabikoviromycin in 7,8 and 9 steps, respectively. During our studies, we discovered a new intramolecular PausonKhand cycloaddition performed on an allene-tethered ynamide substrate to deliver a bicyclo[4.3.0] core. Furthermore, we present a highly regioselective epoxidation employing chiral phase-transfer catalysis to epoxidize streptazone $B_{1}$ to $A$. This in turn enabled the direct reduction of an unprecedented cyclic enaminone functionality using iridium catalysis to access abikoviromycin and dihydroabikoviromycin. Finally, we demonstrate that streptazone A possess several electrophilic sites by in vitro thiol-conju- gation studies. This includes formation of surprising double thiol-adducts that are potentially the result of a cyclopentadienone intermediate.

\section{ASSOCIATED CONTENT}

The Supporting Information is available free of charge at XXX

Experimental details, spectroscopic data, supporting Tables $1-3$, general stabilities etc. is found in supporting information.

\section{AUTHOR INFORMATION}

\section{Corresponding Author}

* Thomas B. Poulsen - Department of Chemistry, Aarhus University, 8ooo Aarhus C, Denmark;

orcid.org/ oooo-ooo2-0763-9996; E-mail: thpou@chem.au.dk

\author{
Authors \\ Gustav J. Wørmer - Department of Chemistry, Aarhus Uni- \\ versity, 8ooo Aarhus C, Denmark \\ Nikolaj L. Villadsen $†$ - Department of Chemistry, Aarhus \\ University, 8000 Aarhus C, Denmark \\ Peter Nørby - Department of Chemistry, Aarhus University, \\ 8000 Aarhus C, Denmark
}

\section{Present Addresses}

† Process Chemistry Development, H. Lundbeck A/S, 2500 Valby, Denmark.

\section{Notes}

The authors declare no competing financial interest.

\section{ACKNOWLEDGMENTS}

This work was supported by grants from the Novo Nordisk Foundation (grant NNF19OCo054782 to T.B.P.) and the Carlsberg Foundation (grant $\mathrm{CF}_{17-0800}$ to T.B.P.). We further thank the K.A. Jørgensen lab for access to chiral stationary phase UPC ${ }^{2}$ and Anders Bodholt Nielsen and Dennis Wilkens Juhl for technical assistance with NMR spectroscopy. Lastly, we thank Troels Skrydstrup lab for technical assistance using the two-chamber system and Jens Christian Kondrup for scientific glassware design. 


\section{REFERENCES}

(1) (a) Nomura, D. K.; Maimone, T. J. Target Identification of Bioactive Covalently Acting Natural Products. Curr. Top Microbiol. Immunol. 2019, 420, 351-374. (b) Gersch, M.; Kreuzer, J.; Sieber, S. A. Electrophilic natural products and their biological targets. Nat. Prod. Rep. 2012, 29, 659-682.

(2) Puder, C.; Krastel P.; Zeeck, A. Streptazones A, B1, B2, C, and D: New Piperidine Alkaloids from Streptomycetes. J. Nat. Prod. 2000, 63, 9, 1258-1260.

(3) Liu, Q.-F.; Wang, J.-D.; Wang X.-J.; Liu, C.-X.; Zhang, J.; Pang, Y.-W.; Yu, C.; Xiang, W.-S. Two new piperidine alkaloids from Streptomyces sp. NEAU-Z4. J. Asian Nat. Prod. Res. 2013, 15, 221224

(4) Perry, J. A.; Koteva, K.; Verschoor, C. P.; Wang, W.; Bowdish, D. M.; Wright, G. D. A macrophage-stimulating compound from a screen of microbial natural products. J. Antibiot. 2014, 68, 1, 4046.

(5) Akiyama, T.; Harada, S.; Kojima, F.; Kinoshita, N.; Hamada, M.; Muraoka, Y.; Aoyagi, T.; Takeuchi, T. Epostatin, new inhibitor of dipeptidyl peptidase II, produced by Streptomyces sp. MJ995OF5. J. Antibiot. 1998, 51, 3, 253-26o.

(6) (a) Maruyama, H.; Okamoto, S.; Kubo, Y.; Tsuji, G.; Fujii, I.; Ebizuka, Y.; Furihata, K.; Hayakawa, Y.; Nagasawa, H.; Sakuda, S. Isolation of abikoviromycin and dihydroabikoviromycin as inhibitors of polyketide synthase involved in melanin biosynthesis by Colletotrichum lagenarium. J. Antibiot. 2003, 56, 9, 801-804. (b) Takahashi, S., Serita, K., Enokita, R., Okaza, T. and Haneishi, T. A new antibiotic, $N$-Hydroxydihydroabikoviromycin. Sankyo Kenkyusho Nempo. 1986, 38, 105-108.

(7) Kanbe, K.; Naganawa, H.; Okami, Y.; Takeuchi, T. Kobutimycins $\mathrm{A}$ and $\mathrm{B}$, new alkaloid antibiotics produced by a streptomyces strain. J. Antibiot. 1992, 45, 10, 1700-1702.

(8) Imai, H.; Fujita, S.; Suzuki, K.; Morioka, M.; Tokunaga, T.; Shimizu, M.; Kadota, S.; Furuya, T.; Saito, T. Hatomamicin (YL0358M-A), a new alkaloid antibiotic: Fermentation, isolation, structure and biological properties. J. Antibiot. 1989, 42, 7, 10431048.

(9) Hong, S.-H.; Ban, Y. H.; Byun, W. S.; Kim, D.; Jang, Y.-J.; An, J. S.; Shin, B.; Lee, S. K.; Shin, J.; Yoon, Y. J.; Oh, D.-C. Camporidines $\mathrm{A}$ and $\mathrm{B}$ : antimetastatic and anti-inflammatory polyketide alkaloids from a gut bacterium of Camponotus kiusiuensis. J. Nat. Prod. 2019, 82, 4, 903-910.

(10) Drautz, H.; Zahner, H.; Kupfer, E.; Kellerschierlein, W. Metabolism products of microorganisms 205. Isolation and structure of streptazolin. Helv. Chim. Acta. 1981, 64, 1752-1765.

(11) (a) Kozikowski, A. P.; Uk Park, P. Total synthesis of streptazolin - an application of the aza-analogue of the ferrier rearrangement. J. Am. Chem. Soc. 1985, 107, 6, 1763-1765. (b) Flann, C. J.; Overman, L. E. Enantioselective total synthesis of streptazolin. The tandem use of iminium ion vinylsilane cyclizations and intramolecular acylations. J. Am. Chem. Soc. 1987, 109, 20, 6115-6118. (c) Yamada, H.; Aoyagi, S.; Kibayashi, C. Stereoselective total synthesis of natural (+)-streptazolin via a palladium-catalyzed enyne bicyclization approach. J. Am. Chem. Soc. 1996, 118, 5, 1054-1059. (d) Huang, S.; Comins, D. L. Total synthesis of $(+)$-streptazolin. Chem. Commun. 2ooo, 7, 569-570. (e) Nomura, I.; Mukai, C. Total synthesis of $( \pm)-8 \alpha$-hydroxystreptazolone. Org. Lett. 2002, 4, 24, 4301-4304. (f) Trost, B. M.; Chung, C. K.; Pinkerton, A. B. Stereocontrolled total synthesis of (+)-streptazolin by a palladium-catalyzed reductive diyne cyclization. Angew. Chem. Int. Ed. 2004, 43, 33, 4327-4329. (g) Li, F.; Warshakoon, N. C.; Miller, M. J. Synthetic application of acylnitroso Diels-Alder derived aminocyclopentenols: Total synthesis of (+)-streptazolin. J. Org. Chem. 2004, 69, 25, 8836-8841. (h) Mitchell, D.; Liebeskind, L. S. (+/-)-
Benzoabikoviromycin, a Potential Antiviral Agent Synthesized by the Palladium-Catalyzed Ring Expansion of 2-Alkynyl-2-Hydroxybenzocyclobutenones. J. Am. Chem. Soc. 1990, 112, 1, 291296.

(12) Abikoviromycin has also been referred to as latumcidin in some earlier papers. In this manuscript, we refer to the compound as abikoviromycin. (a) Sakagami, Y.; Yamaguchi, I.; Yonehara, H.; Okimoto, Y.; Yamanouchi, S.; Takiguchi, K.; Sakai, H., Latumcidin, a new antibiotic from Streptomyces sp. J. Antibiot. Ser. A. 1958, 11, 6-13. (b) Umezawa, H.; Tazaki, T.; Fukuyama, S., An antiviral substance, abikoviromycin, produced by Streptomyces species. J. Antibiot. 1952, 5, 469-476. (c) Gurevich, A.; Kolosov, M.; Korobko, V.; Onoprienko, V. The structure of abikoviromycin. Tetrahedron Lett. 1968, 9, 2209-2212.

(13) Ohno, S.; Katsuyama, Y.; Tajima, Y.; Izumikawa, M.; Takagi, M.; Fujie, M.; Satoh, N.; Shin-ya, K.; Ohnishi, Y. Identification and characterization of the streptazone $\mathrm{E}$ biosynthetic gene cluster in Streptomyces sp. MSCo90213JEo8. ChemBioChem. 2015, 16, 23852391.

(14) Selected examples: (a) Witulski, B.; Stengel, T. N-functionalized 1-Aalkynylamides: New building blocks for transition metal mediated inter- and intramolecular $[2+2+1]$ cycloadditions. Angew. Chem. Int. Ed. 1998, 37, 489-492. (b) Frederick, M. O.; Mulder, J. A.; Tracey, M. R.; Hsung, R. P.; Huang, J.; Kurtz, K. C.; Shen, L.; Douglas, C. J. A copper-catalyzed C-N bond formation involving sp-hybridized carbons. A direct entry to chiral ynamides via N-alkynylation of amides. J. Am. Chem. Soc. 2003, 125, 23682369. (c) Dunetz, J. R.; Danheiser, R. L. Copper-mediated N-alkynylation of carbamates, ureas, and sulfonamides. A general method for the synthesis of ynamides. Org. Lett. 2003, 5, 40114014. (d) Istrate, F. M.; Buzas, A. K.; Jurberg, I. D.; Odabachian, Y.; Gagosz, F. Synthesis of functionalized oxazolones by a sequence of $\mathrm{Cu}(\mathrm{II})-$ and $\mathrm{Au}(\mathrm{I})$-catalyzed transformations. Org. Lett. 20o8, 10, 925-928. (e) Mansfield, S. J.; Smith, R. C.; Yong, J. R. J.; Garry, O. L.; Anderson, E. A. A general copper-catalyzed synthesis of ynamides from 1,2-dichloroenamides. Org. Lett. 2019, 21, 29182922. (f) Riddell, N.; Villeneuve, K.; Tam, W. Ruthenium-catalyzed $[2+2]$ cycloadditions of ynamides. Org. Lett. 2005, 7, 36813684 .

(15) (a) Crabbé, P.; Fillion, H.; André, D.; Luche, J.-L. Efficient homologation of acetylenes to allenes. J. Chem. Soc., Chem. Commun. 1979, 19, 859-86o. (b) Li, M.; Dixon, D. J. Stereoselective spirolactam synthesis via palladium catalyzed arylative allene carbocyclization cascades. Org. Lett. 2010, 12, 3784-3787.

(16) (a) Zhang, Y.; Hsung, R. P.; Tracey, M. R.; Kurtz, K. C. M.; Vera, E. L. Copper sulfate-pentahydrate-1,10-phenanthroline catalyzed amidations of alkynyl bromides. Synthesis of heteroaromatic amine substituted ynamides. Org. Lett. 2004, 6, 1151-1154. (b) Zhang, X.; Zhang, Y.; Huang, J.; Hsung, R. P.; Kurtz, K. C. M.; Oppenheimer, J.; Petersen, M. E.; Sagamanova, I. K.; Shen, L.; Tracey, M. R. Copper(II)-catalyzed amidations of alkynyl bromides as a general synthesis of ynamides and Z-enamides. An intramolecular amidation for the synthesis of macrocyclic ynamides. J. Org. Chem. 2006, 71, 4170-4177. (c) Dooleweerdt, K.; Birkedal, H.; Ruhland, T.; Skrydstrup, T. Irregularities in the effect of potassium phosphate in ynamide synthesis. J. Org. Chem. 2oo8, 73, 9447-9450.

(17) Brummond, K. M.; Chen, H.; Fisher, K. D.; Kerekes, A. D.; Rickards, B.; Sill, P. C.; Geib, S. J. An allenic Pauson-Khand-type reaction: A reversal in $\pi$-bond selectivity and the formation of seven-membered rings. Org. Lett. 2002, 4, 1931-1934.

(18) Kitagaki, S.; Inagaki, F.; Mukai, C. [2+2+1] Cyclization of allenes. Chem. Soc. Rev. 2014, 43, 2956-2978.

(19) Bayden, A. S.; Brummond, K. M.; Jordan, K. D. Computational insight concerning catalytic decision points of the transition 
metal catalyzed $[2+2+1]$ cyclocarbonylation reaction of allenes. Organometallics, 2006, 25, 5204-5206.

(20) Hermange, P.; Lindhardt, A. T.; Taaning, R. H.; Bjerglund, K.; Lupp, D.; Skrydstrup, T. Ex situ generation of stoichiometric and substoichiometric ${ }^{12} \mathrm{CO}$ and ${ }^{13} \mathrm{CO}$ and its efficient incorporation in palladium catalyzed aminocarbonylations. J. Am. Chem. Soc. 2011, 133, 6061-6071.

(21) Gupta, A. K.; Park, D. I.; Oh, C. H. The exclusive formation of cyclopentenones from molybdenum hexacarbonyl-catalyzed Pauson-Khand reactions of 5-allenyl-1-ynes. Tetrahedron Lett. 2005, 46, 4171-4174.

(22) Hjerrild, P.; Tørring, T.; Poulsen, T. B. Dehydration Reactions in Polyfunctional Natural Products. Nat. Prod. Rep. 2o2o, 37, 8, 1043-1064.

(23) (a) Zhang, W.; Loebach, J. L.; Wilson, S. R.; Jacobsen, E. N. Enantioselective epoxidation of unfunctionalized olefins catalyzed by (salen)manganese complexes. J. Am. Chem. Soc. 1990, 112, 2801-2803. (b) Brandes, B. D.; Jacobsen, E. N. Highly enantioselective, catalytic epoxidation of trisubstituted olefins. J. Org. Chem. 1994, 59, 4378-4380.

(24) Bougauchi, M.; Watanabe, S.; Arai, T.; Sasai, H.; Shibasaki, M. Catalytic asymmetric epoxidation of $\alpha, \beta$-unsaturated ketones promoted by lanthanoid complexes. J. Am. Chem. Soc. 1997, 119, 23292330.

(25) (a) Hummelen, J. C.; Wynberg, H. Alkaloid assisted asymmetric synthesis IV additional routes to chiral epoxides. Tetrahedron Lett. 1978, 19, 1089-1092. (b) Lygo, B.; Wainwright, P. G. Asymmetric Phase-Transfer Mediated Epoxidation of $\alpha, \beta$-Unsaturated Ketones Using Catalysts Derived from Cinchona Alkaloids. Tetrahedron Lett. 1998, 39, 12, 1599-1602. (c) Lygo, B.; Wainwright, P. G. Phase-Transfer Catalysed Asymmetric Epoxidation of Enones Using N-Anthracenylmethyl-Substituted Cinchona Alkaloids. Tetrahedron, 1999, 55, 20, 6289-6300.

(26) Cacchi, S.; Morera, E.; Ortar, G. Palladium-catalyzed reduction of enol triflates to alkenes. Tetrahedron Lett. 1984, 25, 48214824 .

(27) Scott, W. J.; Stille, J. K. Palladium-catalyzed coupling of vinyl triflates with organostannanes. Synthetic and mechanistic studies. J. Am. Chem. Soc. 1986, 108, 3033-3040.
(28) Das, S.; Addis, D.; Zhou, S.; Junge, K.; Beller, M. Zinc-catalyzed reduction of amides: Unprecedented selectivity and functional group tolerance. J. Am. Chem. Soc. 2010, 132, 1770-1771.

(29) Schedler, D. J. A.; Godfrey, A. G.; Ganem, B. Reductive deoxygenation by $\mathrm{Cp}_{2} \mathrm{ZrHCl}$ : Selective formation of imines via zirconation/hydrozirconation of amides. Tetrahedron Lett. 1993, 34, 5035-5038.

(30) Focken, T.; Charette, A. B. stereoselective synthesis of pyridinones: application to the synthesis of (-)-barrenazines. Org. Lett. 2006, 8, 2985-2988.

(31) Lipshutz, B. H.; Chrisman, W.; Noson, K.; Papa, P.; Sclafani, J. A.; Vivian, R. W.; Keith, J. M., Copper hydride-catalyzed tandem 1,4-reduction/alkylation reactions. Tetrahedron, 20oo, 56, 27792788.

(32) Tsuruoka, T.; Shomura, T.; Ogawa, Y.; Ezaki, N.; Watanabe, H.; Amano, S.; Inouye, S.; Niida, T. Some properties of SF-973 B substance, the enzyme catalyzing the conversion of dihydroabikoviromycin to abikoviromycin. J. Antibiot. 1973, 26, 168-174. (33) He, C.; Stratton, T. P.; Baran, P. S. Concise total synthesis of herqulines B and C. J. Am. Chem. Soc. 2018, 141, 29-32.

(34) Cheng, C.; Brookhart, M. Iridium-catalyzed reduction of secondary amides to secondary amines and imines by diethylsilane. J. Am. Chem. Soc. 2012, 134, 11304-11307.

(35) (a) Holmalahti, J.; Mäki-Paakkanen, J.; Kangas, L.; von Wright, A. Genotoxicity of dihydroabikoviromycin, a secondary metabolite of Streptomyces Anulatus. Mutat. Res-Genet. Tox. 1996, 368, 157-163. (b) Holmalahti, J.; Raatikainen O.; von Wright, A.; Laatsch, H.; Spohr, A.; Lyngberg, O. K.; Nielsen, J. Production of dihydroabikoviromycin by Streptomyces Anulatus: Production parameters and chemical characterization of genotoxicity. J. App. Microbiol. 1998, 85, 61-68.

(36) Isobe, Y.; Okumura, M.; McGregor, L. M.; Brittain, S. M.; Jones, M. D.; Liang, X.; White, R.; Forrester, W.; McKenna, J. M.; Tallarico, J. A.; Schirle, M.; Maimone, T. J.; Nomura, D. K. Manumycin polyketides act as molecular glues between UBR7 and P53. Nat. Chem. Biol. 2020, 16, 1189-1198. 


Divergent thiol reactivity
allene-ynamide
Pauson-Khand

